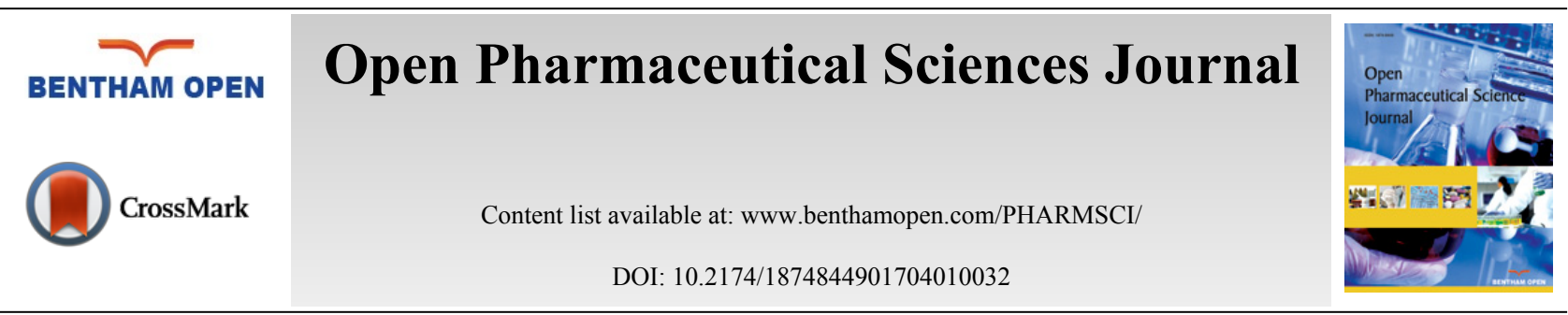

RESEARCH ARTICLE

\title{
High Performance Liquid Chromatography (HPLC) Stability Indicating Method for the Determination of Bromazepam Via its Copper (II) Chelates
}

Assefa Takele ${ }^{1}$, Abdel-Maaboud I. Mohamed Attaya ${ }^{2}$, Ariaya Hymete ${ }^{3}$ and Melisew Tadele Alula $^{4,5, *}$

${ }^{I}$ Department of Chemistry \& Pharmacy; Faculty of Science and Technology, University of Algarve, Faro, Portugal

${ }^{2}$ Department of Pharmaceutical Analytical Chemistry, Faculty of Pharmacy, Assiut University, Assiut, Egypt

${ }^{3}$ Department of Pharmaceutical Chemistry, School of Pharmacy, Addis Ababa University, Addis Ababa, Ethiopia

${ }^{4}$ Department of Chemical and Forensic Sciences; College of Science, Botswana International University of Science and Technology, Palapye, Botswana

${ }^{5}$ Department of Chemistry; College of Science; Bahir Dar University, Bahir Dar, Ethiopia

Received: January 19, 2017

Revised: March 08, 2017

Accepted: March 31, 2017

Abstract:

Introduction:

Bromazepam is hydrolyzed in acidic aqueous solution leading to a series of degradation products. The rate of acidic hydrolysis is believed to be dependent on the state of protonation of the pyridyl and azomethine nitrogen atoms. Stability test is important in pharmaceutical industry to provide evidence on how the quality of an active substance or pharmaceutical product varies with time under the influence of a variety of environmental factors.

\section{Objective:}

The aim of the study was to develop a simple stability indicating method for the determination of bromazepam.

\section{Method:}

Bromazepam solution was prepared and forced degradation of bromazepam was performed under acid hydrolysis using sulphuric acid. High performance liquid chromatography determination of pure and degraded bromazepam and bromazepam-copper (II) complex was performed using reversed phase octyl C-8 column under isocratic conditions and the chromatographic conditions were set as follows; the flow rate of the mobile phase was $1.5 \mathrm{~mL} / \mathrm{min}$; injection volume was $10 \mu \mathrm{L}$, column temperature was $30^{\circ} \mathrm{C}$ and the detector wavelength being $309 \mathrm{~nm}$.

\section{Results:}

Bromazepam, its degradation product and bromazepam chelated with copper (II) were determined using the developed mobile phase with flow rate of $1.5 \mathrm{~mL} / \mathrm{min}$. Good separation with sharp peak, minimum tailing and retention time repeatability was obtained. The rate order, rate constant and half-life of degradation were also determined, and it was observed that the degradation reaction follows the first order kinetics.

\footnotetext{
* Address correspondence to this author at the Department of Chemical and Forensic Sciences; College of Science, Botswana International University of Science and Technology, Palapye, Plot 10071, Private Bag 16, Botswana; Tel: +26777424353; Fax: +267-4900102; E-mails: alulam@biust.ac.bw, melisewt2004@yahoo.com
} 


\section{Conclusion:}

Chromatographic separation of bromazepam chelated with copper (II) was achieved and the method can be further used in drug manufacturing quality control.

Keywords: Bromazepam, HPLC, Method development, Stability, Anxiolytics, Kinetic study.

\section{INTRODUCTION}

Anxiolytics are drugs used to relieve anxiety or prevent anxiety attack which is broadly defined as a state of unwarranted or inappropriate worry, often accompanied by restlessness, tension, destruction, irritability, and sleep disturbances [1]. Benzodiazepines are among the most frequently used psychotropic drugs because of their efficiency, rapid effect and low toxicity. Since the introduction of the first benzodiazepine, chlordiazepoxide, in 1960, more than 50 benzodiazepine drugs has been made available for the treatment of anxiety.

Bromazepam $\left(\mathrm{C}_{14} \mathrm{H}_{10} \mathrm{BrN}_{3} \mathrm{O}\right)$, chemically known as 7-bromo-1, 3-dihydro-5(2-pyridyl)-2H-1, 4-benzodiazepin-2one, is a member of the 1, 4-benzodiazepine drug that was first synthesized by Fryer, in 1964 [2, 3]. Bromazepam, like most of the benzodiazepine derivatives, is hydrolyzed in acidic aqueous solution leading to a series of degradation products [2]. The rate of acidic hydrolysis of bromazepam is believed to be dependent on the state of protonation of the pyridyl and azomethine nitrogen atoms [4, 5]. It is hydrolyzed in acidic condition via intermediate product to give the final product of 2(2-amino-5-bromobenzoyl) pyridine (II) and glycine [6, 7].

Different methods such as non-aqueous titration [8] flow injection [9], sequential injection [10], voltammetric [4, 11], spectrophotometric [12,13], chromatographic [14 - 16], capillary electrophoresis [17], and ion selective sensor methods [18] have been reported for the determination of bromazepam in pharmaceutical preparations, blood and plasma. Though BP recommends non-aqueous titration and spectrophotometric methods for the analysis of bromazepam in raw materials [8], there is no official method for its analysis in tablets.

In addition to determination of the active components in a specific drug, stability test is important in pharmaceutical industry to provide evidence on how the quality of an active substance or pharmaceutical product varies with time under the influence of a variety of environmental factors such as temperature, humidity, and light.

Although different chromatographic methods such as thin layer chromatography (TLC) [19, 20], HPTLC [21, 22], and gas chromatography (GC) $[23,24]$ have been reported for stability indicating assay, their application is limited; for example, the variability and non-quantitative nature of TLC, expensiveness of HPTLC, and thermally unstability of the drug in case of GC can be taken as limitations.

Alternatively, HPLC has been very widely employed. It has been used in stability studies due to its high resolution capacity, sensitivity and specificity. Non- volatile, thermally unstable or polar/ionic compounds can also be analyzed by this technique. Therefore, most of the stability indicating assay methods have been established using HPLC [25, 26]. Therefore, in this study, we developed a simple analytical and stability indicating method for the determination of bromazepam based on bromazepam-copper (II) complex formation using the $-\mathrm{N}=\mathrm{C}-\mathrm{C}=\mathrm{N}$ - moiety, that enables bromazepam to form complex with some divalent metal ions such as copper (II), cobalt (II), nickel (II) and iron (II) [11].

\section{EXPERIMENTAL}

\subsection{Chemicals and Solvents}

Bromazepam (of 99.3\% purity) working standard was obtained from Remedica Pharmaceuticals Ltd. (Remedica, Cyprus). HPLC grade methanol and acetonitrile, methanol absolute acetone free, copper (II) nitrate, ammonium acetate, potassium dihydrogen phosphate, glacial acetic acid, sodium hydroxide, chloroform and acetone were purchased from Fisher Scientific (UK). Sulfuric acid was obtained from BDH (England). Bromazepam tablets (Lexotanil ${ }^{\mathbb{Q}}$, Roche, Switzerland) were obtained from local pharmacy in Addis Ababa, Ethiopia. Deionized water was used throughout the experimental works.

\subsection{Instruments and Equipment}

Spectronic unicam Ultraviolet-visible double beam spectrophotometer (model number-UVA 083430 type Helison alpha) using $1 \mathrm{~cm}$ quartz cells was used to obtain UV-visible spectra by scanning from 200 to $500 \mathrm{~nm}$ wavelength 
range. HPLC with Ultraviolet-visible detector (Shimadzu, Class VP, Japan) equipped with degasser unit (DGU-20As), pumping system (LC-20AT), auto sampler unit (SIL-20A), column oven (CTO-20AC), Ultraviolet-visible detector (SPD-20AV), communication bus module (CBM-20A), personal computer installed with class VP software for data integration and analysis was used for HPLC analysis.

\subsection{Preparations of Solutions}

\subsubsection{Preparation of Bromazepam-Copper (II) Complex}

Initially $500 \mu \mathrm{g} / \mathrm{mL}$ methanolic standard bromazepam solution was prepared and the working solutions were prepared from the standard solution just before the experiments. Similarly standard copper (II) solution was prepared by dissolving $60.5 \mathrm{mg}$ of copper (II) nitrate in $50 \mathrm{~mL}$ volumetric flask using methanol as the solvent. From these solutions bromazepam- $\mathrm{Cu}$ (II) complex was prepared.

\subsubsection{Preparation of Degraded Bromazepam Solution for Kinetic Study}

Forced degradation of bromazepam was performed under acid hydrolysis using $10 \mathrm{~N}$ sulphuric acid. Laboratory degraded bromazepam solution $(200 \mu \mathrm{g} / \mathrm{mL})$ was prepared by taking $50 \mathrm{mg}$ of pure bromazepam in a quick fit flask and then adding $10 \mathrm{~mL}$ of $10 \mathrm{~N}$ sulfuric acid. This solution was refluxed in boiling water bath for 3 hours and then neutralized with $10 \mathrm{~N}$ sodium hydroxide. The mixture was then quantitatively transferred into a separatory funnel and extracted with $15 \mathrm{~mL}$ diethyl ether three times by shaking with magnetic shaker for 10 minutes. The ether extracts (upper layers) were collected in an evaporating dish and evaporated to dryness in a hot water bath (approximately $50^{\circ} \mathrm{C}$ ) and dried in a vacuum desiccator over sulfuric acid for 30 minutes. Finally, the residue was transferred to a $250 \mathrm{ml}$ volumetric flask with methanol. The degraded was tested for its complete degradation by TLC using silica gel $60 \mathrm{~F}_{254}$ plates and a mobile phase of chloroform: acetone $(4: 1, \mathrm{v} / \mathrm{v})$, and chloroform: methanol $(2: 1, \mathrm{v} / \mathrm{v})$. The developed plate was visualized under UV light at $254 \mathrm{~nm}$.

\subsubsection{Sample Preparation Using the Dosage Form}

Twenty tablets were taken and their mean weight was determined. They were powdered with mortar and pestle and mixed to homogeneity. The powdered tablets equivalent to $25 \mathrm{mg}$ of bromazepam was weighed and transferred into a $250 \mathrm{~mL}$ beaker. The drug from the powder was extracted three times with $80 \mathrm{~mL}$ of methanol at a time. To ensure complete extraction of the drugs, the mixture was sonicated for about 20 minutes before separation of the two phases. Whatman filter paper wetted with methanol was used to filter the resulting methanol extract and diluted in $250 \mathrm{~mL}$ volumetric flask using methanol.

\subsection{Chromatographic Condition}

Chromatographic separation of bromazepam chelated with copper (II) was performed using reversed phase octyl C-8 column (Beckman) ( $250 \times 4.6 \mathrm{~mm}$ internal diameter and $5 \mu \mathrm{m}$ particle size). Separation was achieved under isocratic conditions using a mobile phase consisting of a mixture of HPLC grade methanol and acetonitrile, and buffer (26.5:21.5:52). The buffer was composed of $0.005 \mathrm{M}$ potassium dihydrogen phosphate and $0.1 \mathrm{M}$ ammonium acetate adjusted to $\mathrm{pH} 6.2$ with $0.1 \mathrm{M}$ glacial acetic acid. The mobile phase was filtered through a $0.45 \mu \mathrm{m}$ Millipore filter and degassed in ultrasonic bath prior to use. HPLC measurements were done by setting the conditions as follows: the flow rate of the mobile phase was $1.5 \mathrm{~mL} / \mathrm{min}$; injection volume was $10 \mu \mathrm{L}$, column temperature was $30^{\circ} \mathrm{C}$ with the detector wavelength of $309 \mathrm{~nm}$. Then, the condition of chromatographic system assumed to give good separation efficiency such as good resolution between peaks, minimum tailing or fronting and retention time repeatability were optimized.

\subsection{UV-Visible Spectrophotometry and HPLC Measurements}

\subsubsection{UV-Visible Spectrophotometric Measurement of Pure Bromazepam Solution}

The maximum absorbance of bromazepam solution was determined from working solutions of bromazepam of concentration 10,15,20,30, 40 and $50 \mu \mathrm{g} / \mathrm{mL}$. Similarly, for the degraded bromazepam solution, three solutions of concentrations 16,20 and $50 \mu \mathrm{g} / \mathrm{mL}$ were taken and scanned with the same wavelength range.

\subsubsection{UV-Visible Spectrophotometric Measurement Bromazepam-Copper (II) Complex}

A range of bromazepam solution $(10$ to $50 \mu \mathrm{g} / \mathrm{mL})$ were prepared and transferred to $50 \mathrm{~mL}$ volumetric flasks 
followed by addition of $2.5 \mathrm{~mL}$ of copper (II) nitrate stock solution and completed to volume with methanol and then scanned. Similarly, for the complex of degraded bromazepam with copper (II), degraded bromazepam solution (16, 20 and $50 \mu \mathrm{g} / \mathrm{mL}$ ) were prepared and transferred to a $50 \mathrm{~mL}$ volumetric flasks followed by addition of $2.5 \mathrm{~mL}$ of copper (II) nitrate stock solution and completed to volume with methanol. The resulting solutions were sonicated and absorbance measurements were done.

\subsubsection{HPLC Determination of Pure and Degraded Bromazepam}

For HPLC determination of pure bromazepam 10, 15 and $25 \mathrm{~mL}$ were taken from the working solution and transferred to $50 \mathrm{~mL}$ volumetric flask and completed to volume with methanol. Then the solutions were sonicated for about 20 minutes and filtered through a $0.45 \mu \mathrm{m}$ Millipore filter and injected into the HPLC column. Similarly, for degraded bromazepam 5, 7.5 and $12.5 \mathrm{~mL}$ were taken from the stock solution and transferred to $50 \mathrm{~mL}$ volumetric flask and completed to volume with methanol. Then the solutions were sonicated for about 20 minutes and filtered through a $0.45 \mu \mathrm{m}$ Millipore filter and injected into the HPLC column.

\subsubsection{HPLC Determination of Bromazepam-Copper (II) Complex}

In order to obtain the calibration curve for bromazepam- copper (II) complex, seven working solutions of concentrations $20,25,30,35,40,45$ and $50 \mu \mathrm{g} / \mathrm{mL}$ were prepared and transferred to a $50 \mathrm{~mL}$ volumetric flasks followed by addition of $2.5 \mathrm{~mL}$ of copper (II) nitrate stock solution and completed to volume with methanol. The resulting solutions sonicated for about 20 minutes and filtered through a $0.45 \mu \mathrm{m}$ Millipore filter and injected into the HPLC column.

\subsubsection{HPLC Determination of the Dosage Form}

From the stock sample solution of the dosage form $10 \mathrm{~mL}$ was taken and transferred to a $50 \mathrm{~mL}$ volumetric flask followed by addition of $2.5 \mathrm{~mL}$ of copper (II) nitrate stock solution and completed to volume with methanol. Then the resulting sample solution was sonicated for about 20 minutes and filtered through a $0.45 \mu \mathrm{m}$ Millipore filter and injected in triplicate into the HPLC column.

\section{RESULTS AND DISCUSSION}

\subsection{Spectrophotometric Study}

Initially, spectrophotometric measurements were performed to study the absorption features of bromazepam, degraded bromazepam, copper (II) solution, bromazepam and degraded bromazepam in the presence of copper (II) solution in wavelength range of 200 to $500 \mathrm{~nm}$.

As shown in the UV-visible spectrum of bromazepam in Fig. (1a), two maximum absorption bands were observed at 234 and $325 \mathrm{~nm}$ from which $234 \mathrm{~nm}$ was selected for HPLC determination of bromazepam for it is more intense. Similarly two maximum absorption bands at 237 and $396 \mathrm{~nm}$ were observed for the degradation product of bromazepam as demonstrated in Fig. (1b). Only one maximum absorbance was available for copper (II) solution around $214 \mathrm{~nm}$ (spectrum not shown).

Complex formation of copper (II) with bromazepam with copper (II) resulted in appearance of four bands at wavelengths of 214, 241 and $284 \mathrm{~nm}$ and a small hump at $357 \mathrm{~nm}$ Fig. (1c) and the maximum absorption band at 284 was taken for HPLC study of bromazepam-copper (II) complex for 214 and $241 \mathrm{~nm}$ could be highly dependent on the concentration of copper (II) so that band overlaps would be a problem. The two bands that have been observed for copper (II) and the degraded bromazepam are observed for their mixture UV-visible absorbance spectrum. The formation of no new bands in the mixture as shown on Fig. (1d) confirms that degraded bromazepam cannot form complex with copper (II).

\subsection{Forced Degradation Study}

Forced decomposition studies were conducted to generate degradation products of the drug for the development of stability indicating assay method. These studies are employed under different conditions such as hydrolytic, photolytic and oxidative decomposition. The hydrolytic degradation of a drug can be studied by refluxing the drug in acidic and alkaline conditions. In a similar manner, degradation under neutral condition can be studied by refluxing the drug in water. To test for oxidation, it is suggested to use hydrogen peroxide in the concentration range of 3-30\% and the 
photolytic studies should be carried out by exposure to light $[25,27]$.

In this investigation acid hydrolysis using $10 \mathrm{~N} \mathrm{H}_{2} \mathrm{SO}_{4}$ was carried out for the degradation study of bromazepam. The acid hydrolysis of bromazepam resulted in the formation of 2-amino-5-bromobenzoyl pyridine and glycine [7, 9]. The 2-amino-5-bromobenzoyl pyridine was separated from glycine by extracting with ether to avoid glycine interference.
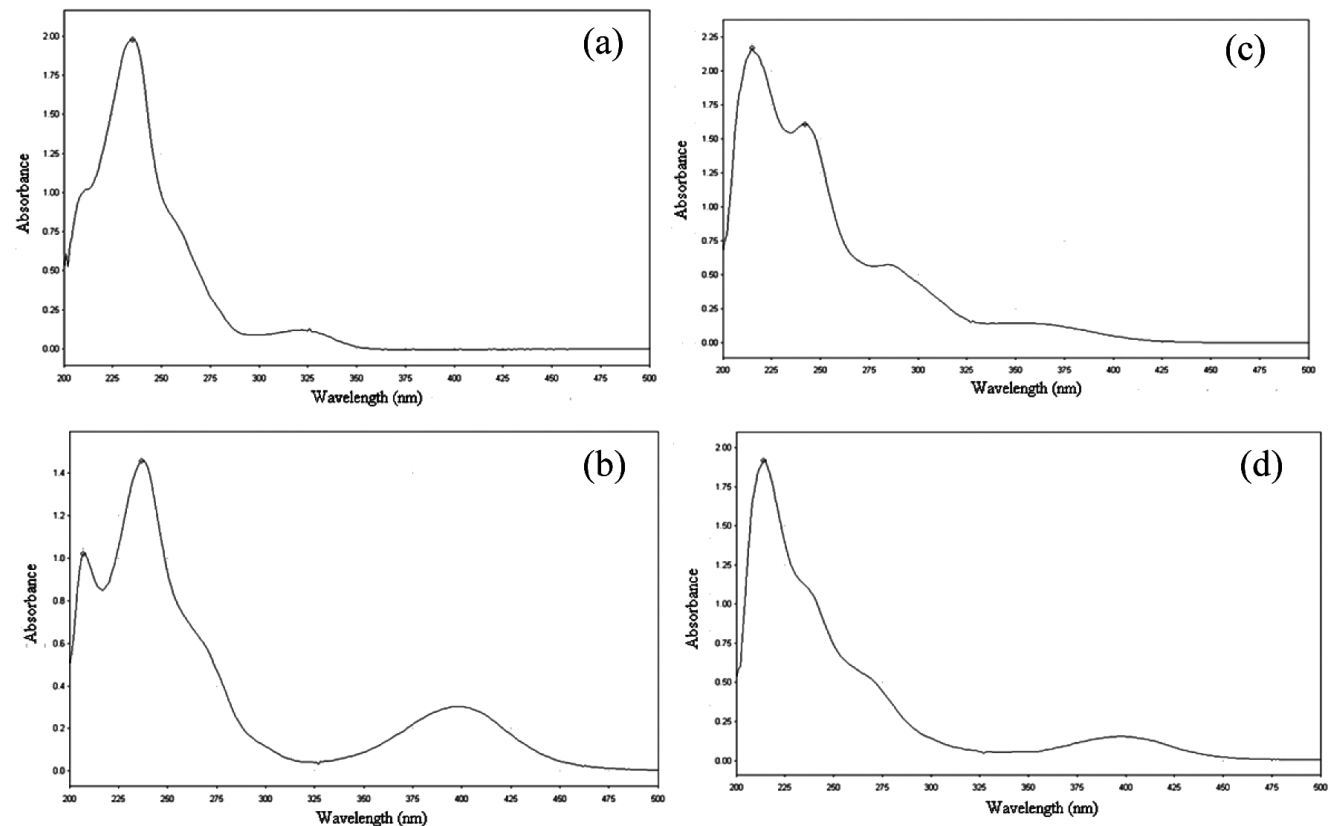

Fig. (1). UV-visible spectra of methanolic solution of $20 \mu \mathrm{g} / \mathrm{mL}$ of (a) intact bromazepam (b) degraded bromazepam (c) intact bromazepam in the presence of $0.0605 \mathrm{mg} / \mathrm{mL}$ of copper (II) and (d) degraded bromazepam in the presence of $0.0605 \mathrm{mg} / \mathrm{mL} \mathrm{of}$ copper (II).

The degraded was tested by TLC using silica gel $60 \mathrm{~F}_{254}$ plates, and the mobile phases chloroform: acetone (4:1, v/v) [7] and Chloroform: methanol (2:1, v/v) [28] for the presence of any undegraded bromazepam. About $20 \mu \mathrm{L}$ from the stock solution of bromazepam, its degradation product obtained by acid hydrolysis and a mixture containing both were applied in form of a band on a silica gel plate. Then it was developed for about 45 minutes. The developed plates were inspected under UV light at $254 \mathrm{~nm}$ and $\mathrm{R}_{\mathrm{f}}$ values for observed spots were calculated.

In chloroform: acetone $(4: 1, \mathrm{v} / \mathrm{v})$, bromazepam gave a blue spot under UV light at $254 \mathrm{~nm}$ at the base line, which was initially colorless solution, where as its degradation product gave a yellow spot with an $\mathrm{R}_{\mathrm{f}}$ value of 0.72 . The mixture gave two spots, blue at the point of application and the other yellow having an $R_{f}$ value of 0.72 .

In chloroform: methanol $(2: 1, \mathrm{v} / \mathrm{v})$, bromazepam gave a blue spot under UV light at $254 \mathrm{~nm}$, at an $\mathrm{R}_{\mathrm{f}}$ of 0.55 , where as its degradation product gave a yellow spot at an $R_{f}$ of 0.84 . The mixture gave spots with the same color and $R_{f}$ value as that of bromazepam and its degradation product. The above TLC results of degradation product showed the absence of any undegraded bromazepan which indicates that the degradation was completed.

Chelation of degraded bromazepam with copper (II) was carried out and did not show any complexation Fig. (1d) or change of color through the adjacent nitrogen and oxygen atoms under the experimental conditions. This is probably because oxygen is more electronegative with a lower electron-donating capability than nitrogen [10]. Hence this renders the stability-indicating assay method more useful for the assay of bromazepam and for checking the extent of its degradation in pharmaceutical preparations.

\subsection{Development and Optimization of the Stability-Indicating HPLC Method}

An isocratic high performance liquid chromatographic method was developed for the determination of bromazepam in the presence of its degradation products by chelation with copper (II). To optimize the HPLC assay parameters the type of column and its dimension, mobile phase condition and choice of wavelength of detection from spectrophotometric measurements were investigated. 
Different types of columns were used, such as ODS-2 C-18 column (Inertrsil), ODS C-18 column (Beckman) and octyl C-8 column (Beckman) with 250 x $4.6 \mathrm{~mm}$ internal diameter and $5 \mu \mathrm{m}$ particle size.

Different mobile phases with different composition were used, such as acetonitrile and methanol (3:1, v/v); acetonitrile, methanol and $0.1 \mathrm{M}$ acetic acid $(3: 1: 1, \mathrm{v} / \mathrm{v} / \mathrm{v})$; methanol, acetonitrile and a mixture of potassium dihydrogen phosphate and ammonium acetate in the ratio $2: 1: 1,1: 2: 1$ and 26.5:21.5:52 (v/v/v) by adjusting the $\mathrm{pH}$ with glacial acetic acid. The injection volume was varied from 5 to $20 \mu \mathrm{L}$, and the flow rate varied from 0.8 to $2 \mathrm{~mL} / \mathrm{min}$. The temperature was varied from 25 to $35^{\circ} \mathrm{C}$ and that of run time was also varied from 10 to 25 minutes.

We followed Panderi et al. [2] procedure to optimize the conditions for the chromatographic system and resulted in good separation efficiency such as good resolution between peaks, minimum tailing or fronting and retention time repeatability.
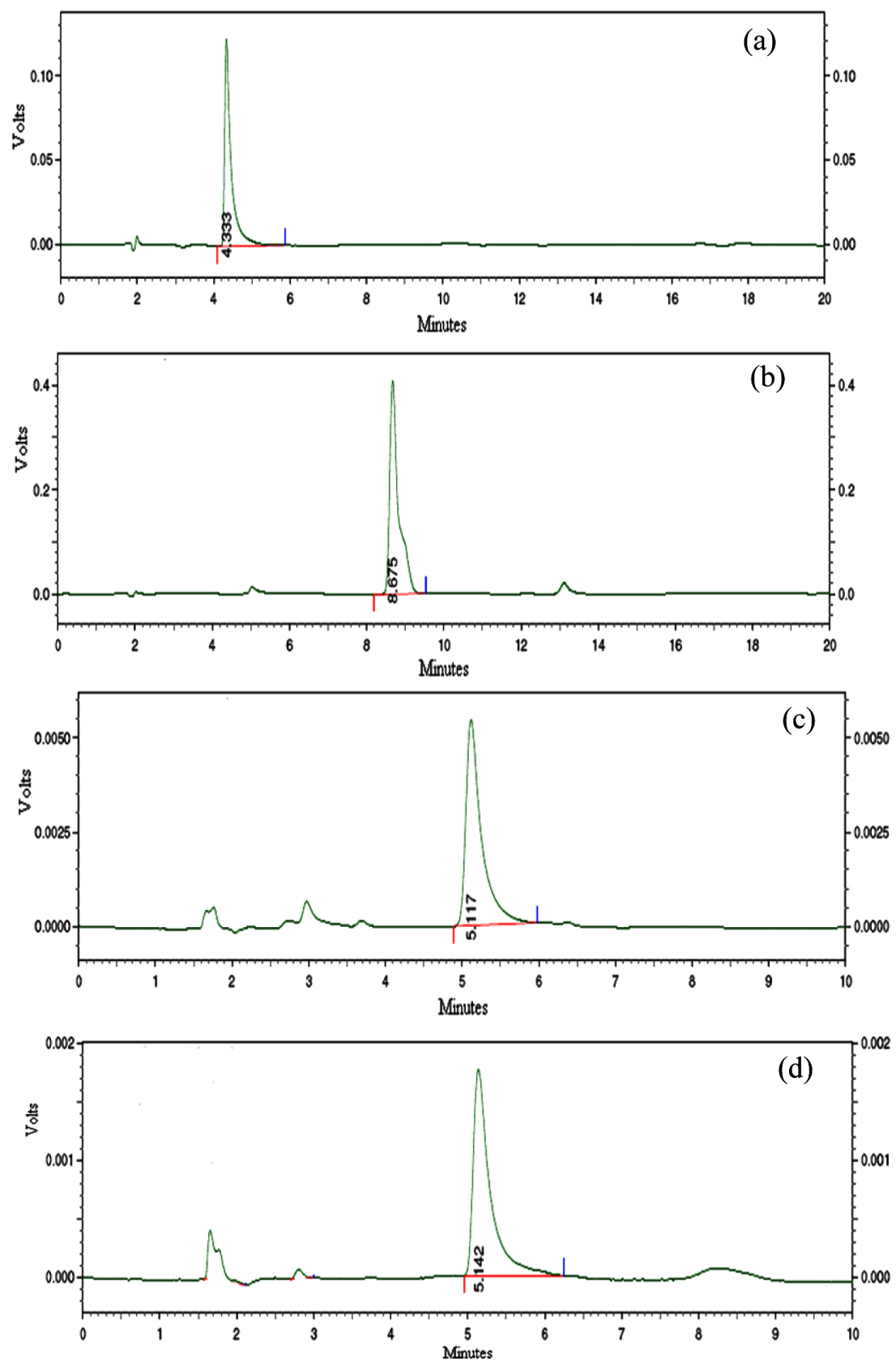

Fig. (2). Typical chromatogram of bromazepam (a), degraded bromazepam (b), and bromazepam chelated with copper (II) at $284 \mathrm{~nm}$ (c) and at $309 \mathrm{~nm}(\mathbf{d})$. 


\subsection{HPLC Determination}

Based on the UV-visible spectrophotometric results, bromazepam, its degradation product and bromazepam chelated with copper (II) were determined using the developed mobile phase with flow rate of $1.5 \mathrm{~mL} / \mathrm{min}$. The detector was set at $234 \mathrm{~nm}$ for the determination of bromazepam and its degradation product, and wavelengths of 284 and 309 $\mathrm{nm}$ were used for the determination of bromazepam chelated with copper (II) as shown in Fig. (2). Good separation with sharp peak, minimum tailing and retention time repeatability was obtained. Retention time for bromazepam and for its degradation was found to be 4.333 and 8.675 min respectively. Bromazepam chelated with copper (II) had almost the same retention time of 5.117 and $5.142 \mathrm{~min}$ at wavelengths of 284 and $309 \mathrm{~nm}$ respectively.

\subsection{Hydrolysis of Bromazepam Under Acidic Condition}

Benzodiazepines are unstable substances, because they easily hydrolyze in acidic solution and also decompose in UV light. Hydrolysis in acidic solution leads generally to 2-aminobenzophenone derivatives, through the splitting of the N1-C2 bond of the diazepine ring [29]. Bromazepam like most of the benzodiazepine derivatives is hydrolyzed in acidic aqueous solutions leading to a series of degradation products. The mechanism of acid hydrolysis of bromazepam proceeds through the intermediate $\mathrm{N}$-(4-bromo-2(2-pyridylcarbonyl) phenyl)-2-aminoacetamide leading to the final products, 2-amino-5-bromobenzoyl pyridine and glycine. As it was reported, formation of the intermediate is very fast while the formation of the final product is rather slow [2].

Kinetic study of bromazepam degradation under acid hydrolysis $\left(10 \mathrm{~N} \mathrm{H}_{2} \mathrm{SO}_{4}\right)$ was carried out at different time points $(30,60,90,120$ and 150 minutes). Degradation was performed by refluxing in boiling water bath for the specified time points separately. After refluxing the solution was neutralized with $10 \mathrm{~N} \mathrm{NaOH}$. Then it was extracted with diethyl ether and evaporated to dryness in a hot water bath and dried over sulfuric acid. Finally the residue was taken up with methanol and determined at a wavelength of $309 \mathrm{~nm}$ and a flow rate of $1 \mathrm{~mL} / \mathrm{min}$. The corresponding HPLC chromatograms of the degradation product after acid hydrolysis are shown in Fig. (3) and the percent peak area of the chromatograms at different time points are recorded Table 1. From the chromatogram it was observed that the retention time of intact bromazepam was $7.265 \pm 0.290$ and that of the degradation product was 2.787 \pm 0.196 .

For kinetic calculations, time zero was considered as the time before degradation and the peak area obtained at zero time was regarded as $100 \%$. Appearance of degradation products and disappearance of the parent compound were analyzed on the basis of percent areas. As observed form Table 1, the HPLC chromatogram percent area versus time profile, after the reaction proceeds for 30 minutes about $60 \%$ of bromazepam and after 60 minutes about $40 \%$ of bromazepam was present in the reaction medium. Thus, within the first 30 minutes, bromazepam decreased rapidly to its degradation product, while after 60 minutes the degradation product increased rapidly and most of bromazepam was actually degraded.

Table 1. Percentage peak area of bromazepam and its degradation product in the chromatogram after degradation at different time points

\begin{tabular}{|c|c|c|}
\hline Time (min) & $\begin{array}{c}\text { Bromazepam } \\
\text { area (\%) }\end{array}$ & $\begin{array}{c}\text { Degradation product } \\
\text { area (\%) }\end{array}$ \\
\hline 0 & 100 & 0 \\
\hline 30 & 63.719 & 33.854 \\
\hline 60 & 40.247 & 52.844 \\
\hline 90 & 19.936 & 60.359 \\
\hline 120 & 9.279 & 87.293 \\
\hline 150 & 5.863 & 94.137 \\
\hline
\end{tabular}

The rate order, rate constant and half-life of degradation were also determined and it was observed that the degradation reaction follows first order kinetics. The rate constant and half-life were calculated from the first order equation and found to be 0.015 and 46.2 minutes respectively.

\subsection{Analysis of Dosage Form}

The proposed method was applied to the determination of bromazepam in marketed formulation (Lexotanil ${ }^{\circledR}$ tablets). The corresponding chromatogram obtained following the assay of bromazepam tablets is shown in Fig. (4). From the experimental results the amount of bromazepam in replicate analysis $(n=3)$ was found to be $98.63 \%$ of the label claim for the tablets and its retention time was found to be $5.003 \pm 0.134$. The retention time found was in a good 
agreement as that was obtained for bromazepam (Fig. 2d). The results of the assay indicate that the method is selective for bromazepam in pharmaceutical dosage forms since it was in good agreement with the label claim without any interference from the excipients which are normally present in tablets.
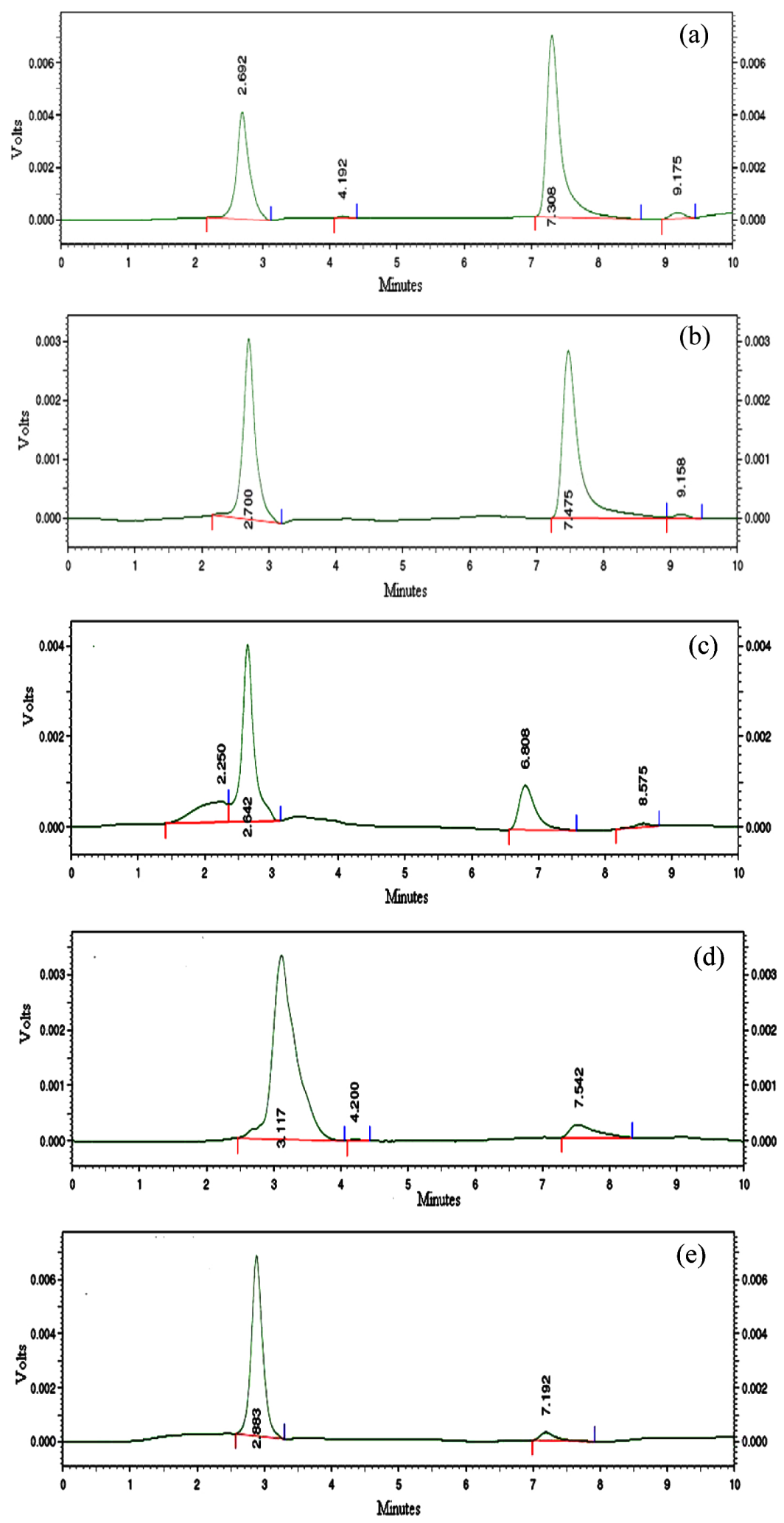

Fig. (3). Chromatogram of degradation products of bromazepam obtained during the kinetic study of acid hydrolysis after 30 (a), 60 (b), 90 (c), 120 (d), and 150 (e) minutes. 


\subsection{Method Validation}

One of the most critical factors in developing pharmaceutical drug substances and products is ensuring that the analytical test methods used to analyze fine chemicals and products generate valid and meaningful data in terms of reliability, accuracy and precision, regardless of whether it is intended for acceptance, release, stability or pharmacokinetic studies [30]. Therefore, in this work validation parameters such as linearity, precision, accuracy, limit of detection and limit of quantitation were used in developing this method and the results are given in supplementary data.

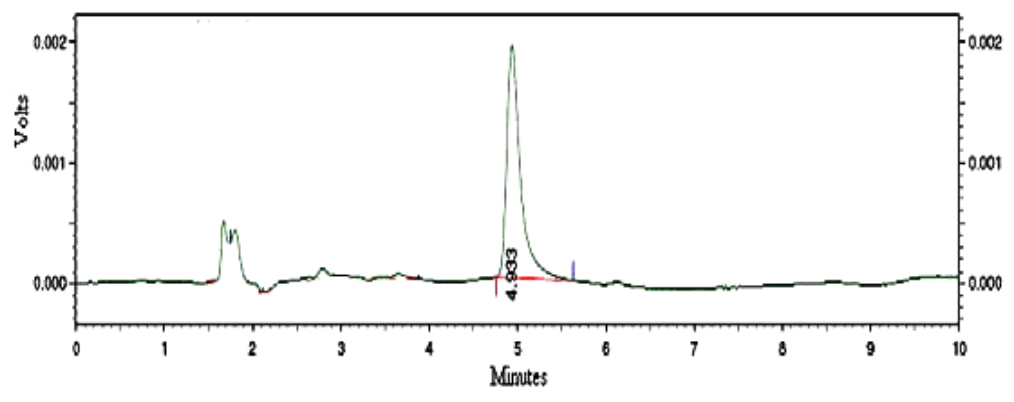

Fig. (4). Chromatogram of bromazepam obtained from analysis of tablet dosage forms.

The linearity of the proposed method was determined by measuring the peak area at different concentration levels. The calibration curve was constructed by plotting mean peak area versus concentration of bromazepam and linear relation for the concentration range of 20 to $50 \mu \mathrm{g} / \mathrm{mL}$ was obtained with correlation coefficient of 0.9976 .

The precision of the proposed method was determined as repeatability (intra-day precision) and intermediate precision (inter-day) and expressed in terms of percentage relative standard deviation (\%RSD) of the peak area. The analyses were performed using concentrations at three levels $(25,35$ and $45 \mu \mathrm{g} / \mathrm{ml})$. Each concentration was analyzed in five replicates $(n=5)$ for intra-day precision and inter-day precision was analyzed in triplicate $(\mathrm{n}=3)$ on three separate days. The results showed that the RSD values for intra-day and inter-day precision were found to be less than $2.15 \%$ and $2.65 \%$, respectively which is within acceptable range.

For determination of accuracy in this method, standard addition method was employed. Thus, equal amount of the dosage form were spiked with three different amounts of the reference standard of the drug product. Later on copper (II) solution was added and subsequently analyzed by the proposed method. Then, the response for both spiked and unspiked preparations have been measured. Accuracy of the method was calculated as percentage recovery from the regression equation and satisfactory recoveries $(94.28-99.74 \%)$ of the spiked drug were obtained at each added concentration level.

Finally, limit of detection and quantitation were determined for bromazepam chelated with copper (II) by the proposed method based on the standard deviation of the response (SD) and the slope of the calibration curve (S) and the limit of detection and quantitation were found to be 3.36 and $11.21 \mu \mathrm{g} / \mathrm{mL}$ respectively.

\section{CONCLUSION}

HPLC stability indicating method was developed for the determination of bromazepam in the tablet dosage forms. Its property to form complex with copper (II) is the essential property for developing this method. Chromatographic separation of bromazepam chelated with copper (II) was best achieved using octyl C-8 column. Determination of kinetic order for degradation of bromazeppam was found to be simple. This method can be further used in drug manufacturing quality control or regulatory analysis laboratory for determination of bromazepam in pharmaceutical dosage forms.

\section{SUPPLEMENTARY MATERIAL}

Supplementary material is available on the publishers Website along with the published article.

\section{CONFLICT OF INTEREST}

The authors confirm that this article content has no conflict of interest. 


\section{ACKNOWLEDGEMENTS}

The authors thank Gulele Education Bureau and Addis Ababa University for the financial support and Ethiopian pharmaceutical manufacturing (EPHARM) for the laboratory facilities.

\section{REFERENCES}

[1] Sandford JJ, Argyropoulos SV, Nutt DJ. The psychobiology of anxiolytic drugs. Part 1: Basic neurobiology. Pharmacol Ther 2000; 88(3): $197-212$.

[http://dx.doi.org/10.1016/S0163-7258(00)00082-6] [PMID: 11337025]

[2] Panderi I, Archontaki H, Gikas E, Parissi-Poulou M. Acidic hydrolysis of bromazepam studied by high performance liquid chromatography. Isolation and identification of its degradation products. J Pharm Biomed Anal 1998; 17(2): 327-35. [http://dx.doi.org/10.1016/S0731-7085(97)00201-X] [PMID: 9638586]

[3] Nevado JJ, Penalvo GC, Bernardo FJ. A contribution on the determination of bromazepam by its ferrous complex formation. Anal Lett 1997; 30: $2515-25$.

[http://dx.doi.org/10.1080/00032719708001762]

[4] Valdeon MJ, Escribano TS, Hernandez L. Determination of bromazepam and its urinary metabolites, with a previous hydrolysis reaction, by voltametric and spectrophotometric techniques. Analyst (Lond) 1987; 112: 1365-8. [http://dx.doi.org/10.1039/AN9871201365]

[5] Smyth MR, Beng TS, Smyth WF. A spectral and polarographic study of the acidbase and complexing behaviour of bromazepam. Anal Chim Acta 1977; 92(1): 129-38. [http://dx.doi.org/10.1016/S0003-2670(01)84579-7] [PMID: 18952]

[6] Tache F, Mutihac L, Medvedovici A, et al. Considerations on MS/MS detection of bromazepam after liquid chromatographic separation from plasma samples: Application to a bioequivalence study. J Liq Chromatogr Tech 2007; 30: 2699-715. [http://dx.doi.org/10.1080/10826070701560603]

[7] Amer MM, Abdel Razek SA. Stability indicating method for the determination of bromazepam via its mercury (ii), silver (i) and zirconium (iv) chelates. Anal Lett 1998; 31: 631-49. [http://dx.doi.org/10.1080/00032719808001867]

[8] British pharmacopoeia. London: Her Majesty’s Stationary Office Publication 2004.

[9] Sultan SM, Suliman FE. Use of sequential injection technique for mechanistic studies and kinetic determination of bromazepam complexed with iron (ii) in hydrochloric acid. Analyst (Lond) 1996; 121: 617-21.

[http://dx.doi.org/10.1039/an9962100617]

[10] Sultan SM. Flow injection stopped-flow kinetic determination of the anxiolytic sedative bromazepam in dosage forms. Analyst (Lond) 1992; 117: 773-6. [http://dx.doi.org/10.1039/an9921700773]

[11] Correia Dos Santos MM, Famila V, Simoes GM. A voltametric study of the complexation of copper by the psychoactive compounds 1,4benzodiazepines. Electroanalysis 2000; 12: 216-22. [http://dx.doi.org/10.1002/(SICI)1521-4109(200002)12:3<216::AID-ELAN216>3.0.CO;2-Q]

[12] Pencheva I, Obreshkova D. Comparative analytical study of bromazepam in pharmaceutical dosage forms. Acta Pharmaceutica Turcica 2002; 44: $52-5$.

[13] Salem AA, Barsoum BN, Izake EL. Spectrophotometric and fluorimetric determination of diazepam, bromazepam and clonazepam in pharmaceutical and urine samples. Spectrochim Acta A Mol Biomol Spectrosc 2004; 60(4): 771-80. [http://dx.doi.org/10.1016/S1386-1425(03)00300-7] [PMID: 15036087]

[14] Andraus MH, Wong A, Silva OA, et al. Determination of bromazepam in human plasma by high-performance liquid chromatography with electrospray ionization tandem mass spectrometric detection: application to a bioequivalence study. J Mass Spectrom 2004; 39(11): 1348-55. [http://dx.doi.org/10.1002/jms.667] [PMID: 15532067]

[15] Zhang XX, Kudo K, Imamura T, Jitsufuchi N, Nagata T. Sensitive determination of bromazepam in human tissues using capillary gas chromatography-mass spectrometry. J Chromatogr B Biomed Appl 1996; 677(1): 111-6. [http://dx.doi.org/10.1016/0378-4347(95)00427-0] [PMID: 8925082]

[16] Chèze M, Villain M, Pépin G. Determination of bromazepam, clonazepam and metabolites after a single intake in urine and hair by LCMS/MS. Application to forensic cases of drug facilitated crimes. Forensic Sci Int 2004; 145(2-3): 123-30. [http://dx.doi.org/10.1016/j.forsciint.2004.04.066] [PMID: 15451083]

[17] Hansen SH, Sheribah ZA. Comparison of CZE, MEKC, MEEKC and non-aqueous capillary electrophoresis for the determination of impurities in bromazepam. J Pharm Biomed Anal 2005; 39(1-2): 322-7. [http://dx.doi.org/10.1016/j.jpba.2005.03.017] [PMID: 15935599]

[18] Al Attas AS. Construction and analytical application of ion selective bromazepam sensor. Int J Electrochem Sci 2009; 4: 20-9.

[19] Fabre H, Hussam-Eddine N. Separation and quantitative determination of dipyrone and its degradation products by thin-layer chromatography. J Pharm Pharmacol 1982; 34: 425-8. 
[http://dx.doi.org/10.1111/j.2042-7158.1982.tb04749.x] [PMID: 6126537]

[20] Baveja SK, Singh S. Thin-layer chromatographic examination of the degradation of centbucridine in aqueous solutions. J Chromatogr A 1987; 396: 337-44.

[http://dx.doi.org/10.1016/S0021-9673(01)94071-3] [PMID: 3624379]

[21] Puthli SP, Vavia PR. Stability indicating HPTLC determination of piroxicam. J Pharm Biomed Anal 2000; $22(4)$ : 673-7. [http://dx.doi.org/10.1016/S0731-7085(99)00300-3] [PMID: 10768357]

[22] Salo JP, Salomies H. High performance thin layer chromatographic analysis of hydrolyzed tinidazole solutions. I. Development and validation method. J Pharm Biomed Anal 1996; 14(8-10): 1261-6.

[http://dx.doi.org/10.1016/S0731-7085(96)01769-4] [PMID: 8818043]

[23] Bergh JJ, Lotter AP. A stability-indicating gas-liquid chromatographic method for the determination of acetaminophen and aspirin in suppositories. Drug Dev Ind Pharm 1984; 10: 127-36. [http://dx.doi.org/10.3109/03639048409038297]

[24] Stavchansky S, Wu P, Wallace JE. Gas liquid chromatographic determination of promethazine hydrochloride in cocoa butter-white wax suppositories. Drug Dev Ind Pharm 1983; 9: 989-98. [http://dx.doi.org/10.3109/03639048309042837]

[25] Bakshi M, Singh S. Development of validated stability-indicating assay methodscritical review. J Pharm Biomed Anal 2002; 28(6): 1011-40. [http://dx.doi.org/10.1016/S0731-7085(02)00047-X] [PMID: 12049968]

[26] Blessy M, Patel RD, Prajapati PN, Agrawal YK. Development of forced degradation and stability indicating studies of drugs-A review. J Pharm Anal 2014; 4: 159-65.

[http://dx.doi.org/10.1016/j.jpha.2013.09.003]

[27] Singh S, Bakshi SM. Guidance on the conduct of stress tests to determine inherent stability of drugs. Pharm Technol 2000; $24: 1-14$.

[28] Fukumato M, Cornning KK. Spectrophotometric determination of bromazepam. Chem Pharm Bull (Tokyo) 1980; 28: 3678-81. [http://dx.doi.org/10.1248/cpb.28.3678]

[29] Hancu G, Gáspár A, Gyéresi A. Separation of 1,4-benzodiazepines by micellar elektrokinetic capillary chromatography. J Biochem Biophys Methods 2007; 69(3): 251-9. [http://dx.doi.org/10.1016/j.jbbm.2006.02.003] [PMID: 16563516]

[30] Shabir GA. Validation of high-performance liquid chromatography methods for pharmaceutical analysis. Understanding the differences and similarities between validation requirements of the US Food and Drug Administration, the US Pharmacopeia and the International Conference on Harmonization. J Chromatogr A 2003; 987(1-2): 57-66. [http://dx.doi.org/10.1016/S0021-9673(02)01536-4] [PMID: 12613797]

(C) 2017 Takele et al.

This is an open access article distributed under the terms of the Creative Commons Attribution 4.0 International Public License (CC-BY 4.0), a copy of which is available at: https://creativecommons.org/licenses/by/4.0/legalcode. This license permits unrestricted use, distribution, and reproduction in any medium, provided the original author and source are credited. 